\title{
EL DERECHO HUMANO AL ACCESO AL AGUA POTABLE: ASPECTOS FILOSÓFICOS Y CONSTITUCIONALES DE SU CONFIGURACIÓN Y GARANTÍA EN LATINOAMÉRICA*
}

\author{
José de Jesús Becerra Ramírez** \\ Irma Salas Benítez ${ }^{* * *}$
}

Fecha de recepción: 6 de abril de 2015

Fecha de evaluación: 3 de septiembre de 2015

Fecha de aprobación: 18 de noviembre de 2015

Artículo de investigación

DOI: http://dx.doi.org/10.18359/prole.1683

Forma de citación: Becerra, J. \& Salas, I. (2016). El derecho humano al acceso al agua potable: aspectos filosóficos y constitucionales de su configuración y garantía en Latinoamérica. Revista Prolegómenos Derechos y Valores, 19, 37, 125-146. DOI: http://dx.doi.org/10.18359/prole.1683

\section{Resumen}

Con base en la doctrina, en algunas de las disertaciones especializadas en derechos fundamentales y en el contenido de los instrumentos universales e interamericanos de protección a los mismos, estas páginas sugieren la justificación y el fundamento del derecho humano al acceso al agua potable como un asunto de dignidad, por lo tanto, un derecho humano y, en específico, un derecho social; así como una aproximación a los estándares mínimos establecidos en el ámbito internacional y las obligaciones que de ellos se derivan para los Estados, que deben garantizar dicho derecho. El abordaje de dichos temas se apoya y sustenta principalmente en los métodos: analítico, para el estudio ordenado y razonado del derecho; fenomenológico, con la finalidad del conocimiento objetivo de su naturaleza y esencia social, y hermenéutico: con el propósito de su estudio a la luz de las interpretaciones realizadas por la doctrina y los órganos supranacionales respecto de su contenido y alcances.

\section{Palabras clave:}

Dignidad humana; derechos económicos, sociales y culturales; garantía.

\footnotetext{
El presente artículo es resultado de los trabajos realizados por el Instituto de Investigación y Capacitación en Derechos Humanos, adscrito a la Comisión Estatal de Derechos Humanos Jalisco, México; dentro del programa interno de investigación, promoción y divulgación de los derechos fundamentales.

* Doctor en Estudios Avanzados en Derechos Humanos por el Instituto de Derechos Humanos Bartolomé de las Casas de la Universidad Carlos III de Madrid, España. Profesor investigador titular C en la Universidad de Guadalajara y miembro del Sistema Nacional de Investigadores en México. Correo electrónico: jesusbecerra@cedhj.org.mx

*** Magíster en Derecho por la Universidad de Guadalajara e investigadora capacitadora adscrita al Instituto de Investigación y Capacitación en Derechos Humanos de la Comisión Estatal de Derechos Humanos Jalisco. Correo electrónico: iicadh@cedhj.org.mx
} 


\title{
HUMAN RIGHT TO THE ACCESS TO DRINKING WATER: PHILOSOPHICAL AND CONSTITUTIONAL ASPECTS OF ITS CONFIGURATION AND WARRANTY IN LATIN AMERICA
}

\begin{abstract}
Summary
Based in the doctrine, in some of the dissertations specialized in fundamental rights and in the contents of universal and Inter American instruments of their protection, these pages suggest the justification and the basis of the human right to the access to drinking water as a dignity subject, and therefore, a human right and, specifically, a social right; in the same way, an approach to the minimum standards established in the international environment and the obligations derived for the States from them, which must guarantee such right. Dealing with such topics is mainly supported on the next methods: analytic, for the ordered and reasoned study of rights; phenomenological, with the aim of objective knowledge of its nature and social essence, and hermeneutic, with the aim of its study on the basis of the interpretations done by the doctrine and supranational organs with respect to its content and scope.
\end{abstract}

\section{Keywords:}

Human dignity, economic, social and cultural rights, warranty.

\section{O DIREITO HUMANO DE ACESSO A ÁGUA POTÁVEL: ASPECTOS FILOSÓFICOS E CONSTITUCIONAIS DE SUA CONFIGURAÇÃO E GARANTIA NA AMÉRICA LATINA}

\begin{abstract}
Resumo
Com base na doutrina e em algumas dissertações especializadas em direitos fundamentais, e no conteúdo dos instrumentos universais e interamericanos de proteção, fica sugerido a justificação $e$ o fundamento do direito humano de acesso à água potável como um assunto de dignidade, $e$ para tanto o foco no direito humano, sendo mais específico um direito social; além disso, uma aproximação aos padrões mínimos estabelecidos no âmbito internacional e das obrigações que derivam para os estados, e que devem assegurar este direito. A abordagem destes temas tem sua base principalmente nos métodos: analíticos, para o estudo ordenado e racional do direito; fenomenológico, com a finalidade de atingir o conhecimento objetivo de sua natureza e essência social, e hermenêutico, que busca o estudo sob a luz das interpretações realizadas pela doutrina e os órgãos supranacionais considerando seu conteúdo e alcance.
\end{abstract}

\section{Palavras-chave:}

Dignidade humana, direitos econômicos, sociais e culturais, garantia. 


\section{Introducción}

Se podría decir que el derecho humano al acceso al agua potable y el saneamiento es de reciente configuración jurídica en el sistema internacional de los derechos humanos, puesto que fue en el 2010 cuando la Organización de las Naciones Unidas (ONU) lo reconoció como tal, por lo que de alguna manera nos encontramos frente a un derecho cuyo contenido y alcances siguen en construcción y especificación. Sin embargo, a dicho reconocimiento precedieron desde 1992 diversas resoluciones, declaraciones, informes y programas que resultaron de cumbres y conferencias del sistema universal de protección a los derechos humanos, y que trataban el acceso al agua potable y el saneamiento como requisito y supuesto para el cumplimiento de otros derechos, mismos que serán abordados y descritos en el apartado posterior de este documento, denominado: "Fundamento internacional del derecho humano al agua".

El acceso al agua potable y a los servicios de saneamiento es sin duda una de las circunstancias que dividen a las personas de vidas saludables y productivas de las que viven en la pobreza, y que son más vulnerables a enfermedades mortales derivadas de la escasez o la mala calidad del agua (Ki-moon, 2007). Aniza García (2008) menciona que la problemática en torno al agua, ocasionada tanto por factores naturales como humanos, es una amenaza al derecho humano que constituye su acceso, y que si bien es cierto que la explotación, deforestación y contaminación de los recursos hídricos son determinantes en la crisis del agua, el elemento primordial de riesgo para la supervivencia de individuos y comunidades es su distribución desigual, pues aunque naturalmente el agua es un recurso limitado, es en realidad a consecuencia de la acción humana que, además de escaso, sea un recurso que no se reparte con justicia (pág. 51).

Por lo anterior, con la intención de participar en el debate académico actual sobre el derecho humano al acceso al agua potable y el saneamiento; las obligaciones del Estado para su garantía y cumplimiento como un asunto de dignidad y como un derecho humano, específicamente un derecho social -de acuerdo con los estándares mínimos considerados por el derecho internacional de los derechos humanos para tal efecto-; y sobre las correlativas responsabilidades internacionales en que pudiera incurrir por acción u omisión el Estado al no lograr su satisfacción, surge la inquietud de desarrollar la presente investigación a partir de los siguientes interrogantes - siendo necesario fundamentar su respuesta en la teoría y la filosofía jurídica de los derechos humanos y los instrumentos internacionales para su protección-: ¿̇por qué es el acceso al agua potable y el saneamiento un asunto de dignidad y, por lo tanto, un derecho humano?; atendiendo su carácter de satisfactor de las necesidades más básicas del sujeto para su bienestar, así como las repercusiones de su acceso o la falta de este en el entorno, la salud y la seguridad de las personas, ¿cuáles son el contenido y los alcances del derecho?; y finalmente ¿́cuál ha sido el tratamiento del derecho humano al acceso al agua potable y el saneamiento respecto de su reconocimiento, garantía y teorización en el ámbito jurídico internacional?

Para contestar dichos cuestionamientos y dar apoyo y sustento al presente trabajo de investigación, se recurrió a los siguientes métodos: analítico, para el estudio ordenado y razonado del contenido del derecho humano al acceso al agua potable y el saneamiento en la doctrina y los instrumentos universales e interamericanos de protección a los derechos humanos; fenomenológico, con la finalidad de conocer de manera objetiva su naturaleza y esencia como un derecho humano social, así como la causa de las dificultades para su garantía en su tratamiento como un bien económico susceptible de ser objeto del mercado cuando en realidad se trata de un bien público; y hermenéutico, para estudiar este derecho humano a la luz de las interpretaciones de la doctrina y los órganos supranacionales jurisdiccionales y no jurisdiccionales para la protección de los derechos humanos respecto de su contenido y alcances. 


\section{A. El acceso al agua potable y el saneamiento: un asunto de dignidad}

A través de toda la historia, el origen de conflictos en el mundo entre individuos, pueblos y poderes, ha sido la demanda del reconocimiento de los derechos y la posibilidad de su ejercicio; de todas aquellas condiciones que permiten a las personas y a los grupos, vivir y desarrollarse plena y dignamente. Es decir, el reclamo del cumplimiento de los derechos humanos, que no son más que la satisfacción de las necesidades humanas más básicas para preservar la vida, la seguridad y las libertades.

Estas necesidades han ido creándose y transformándose según el contexto de vida humana: circunstancias geográficas, políticas, sociales, culturales, económicas y ambientales que pueden contribuir al ejercicio de los derechos, por ser satisfactores a los requerimientos mínimos de las personas; o ser un obstáculo para ello e, incluso, generar nuevas demandas de protección individuales y colectivas. Esto hace que el concepto de dignidad humana, entendido como el conjunto de necesidades de cuya satisfacción depende que la persona se desarrolle en un entorno de bienestar, sea como lo explica Habermas (2010): un concepto inconcluso, inacabado, susceptible de ser ampliado y actualizado con cada nuevo requerimiento humano de protección, pues "diferentes aspectos del significado de la dignidad humana surgen desde la plétora de experiencias de lo que significa ser humillado y herido profundamente" (pág. 8).

De tal forma que, como lo menciona el autor, la dignidad humana tiene una función creativa de derechos, pues estos van surgiendo como satisfactores de las nuevas necesidades que el entorno y el progreso generan en las personas. Complementario a ello, Rolla (2002) señala que la dignidad humana tiene, además, una función verificadora de derechos, porque estos al ser interpretados bajo su luz adquieren nuevos significados y las situaciones en las que se ven vulnerados van actualizándose y propiciando nuevas demandas de tutela (págs. 470-471).
Sin embargo, Pelé (2004) va más allá de la teorización conceptual de la dignidad humana y pone el acento en su concreción en el ámbito jurídico a través de la positivización de los derechos. Para el autor, debido al contraste entre la teórica obviedad del reconocimiento de la igualdad en dignidad y derechos de todas las personas y la práctica, donde por el contrario, son múltiples sus vulneraciones, lo que resulta trascendental no es el concepto, sino los fenómenos jurídicos que retoman el discurso de la "dignidad" como máximo argumento para la exigencia de satisfacción a las necesidades humanas básicas, mediante instrumentos normativos que garanticen una igualdad jurídica y política (págs. 9-13).

En ese mismo sentido, Rolla (2002) atribuye a la dignidad humana, además de un carácter filosófico, un énfasis jurídico, y la estudia desde una perspectiva constitucional que es esencial para efectos de la garantía de su protección. A partir de esta perspectiva, la dignidad humana es considerablemente redimensionada como un principio ya no solo filosófico, sino, además, jurídico; porque cuando el derecho positivo considera expresamente la dignidad humana como un bien específico sujeto a protección y garantía, los alcances de dicha situación optimizan el contenido y alcances de todos los demás bienes y derechos tutelados.

Así mismo, la dignidad humana y su protección se potencializan como un principio interpretativo que vincula a todo el ordenamiento y que, por ello, contribuye a fortalecer el parámetro de validez de las normas, al constituirse como un elemento sustancial de todas aquellas que reconocen, protegen y garantizan derechos humanos, dotándoles de mayor fuerza que a las demás disposiciones, lo que se refleja en preceptos tanto para el reconocimiento $y$ protección de los derechos, como en límites a las discrecionalidades de los legisladores en su regulación (págs. 463-465).

Este hecho se confirma desde el ámbito jurídico por el Tribunal Constitucional Español sobre aquellos derechos o contenidos relativos a la vida, 
la integridad física y moral, la intimidad, la tutela judicial efectiva, la seguridad jurídica, la libertad y la igualdad, entre otros; todos imprescindibles para garantizar la dignidad como un mínimo invulnerable proyectado mediante un mandato imperativo constitucional que se impone a todos los poderes (Pleno del Tribunal Constitucional Español, 2007: pág. 65) ${ }^{1}$.

Ahora bien, atendiendo al tema del acceso al agua potable y el saneamiento, tenemos que este se relaciona con todas y cada una de las actividades y las necesidades del ser humano, un elemento vital sin el cual simplemente no se puede sobrevivir, menos vivir dignamente. Es decir, desde la óptica de Habermas (2010) para la conceptualización de la dignidad humana, antes explicada, que parte de las necesidades que tiene la persona y la influencia que sobre estas ejercen para fines de su satisfacción o insatisfacción las circunstancias del entorno, el acceso al agua potable constituiría una de estas necesidades básicas de cuya satisfacción depende el bienestar de la persona, más aún en un contexto que, lejos de contribuir a la solución de dicha necesidad, resulta ser, desde los diferentes enfoques con que se observe, inadecuado para garantizar su acceso en calidad de derecho humano.

Lo anterior debido, entre otras cosas, a: la escasez en la disponibilidad del recurso y su contaminación; los problemas de salud derivados de ello, enfermedades ocasionadas por el contacto con agua contaminada o su consumo e, inclusive, por la falta de su acceso para la supervivencia y para mantener las condiciones de higiene adecuadas en el entorno, los alimentos y la propia persona; también lo exiguo de la cobertura del servicio a través del cual se materializa el derecho humano y la necesidad de ampliar y modernizar infraestructuras obsoletas e ineficientes para su prestación; o el monto de las asignaciones presupuestarias para su garantía en relación con las

1 Nos referimos específicamente a las sentencias: STC107/1984, STC-99/1985, STC-91/2000, STC-95/2003, STC-144/1990 y STC-137/2000, todas citadas en: sentencia 236/2007 (Pleno del Tribunal Constitucional Español, 7 de noviembre de 2007). destinadas a hacer efectivos otros derechos; las prácticas discriminatorias en la gestión del recurso; poca práctica y experiencia en su exigibilidad jurisdiccional, y el insuficiente conocimiento y sensibilización en el tema de la sociedad civil, los operadores jurídicos y los servidores públicos. De tal manera que el acceso al agua potable es un asunto de dignidad porque, atendiendo al contexto y la problemática actual de disponibilidad y gestión del agua, las necesidades en cuanto a su acceso se han intensificado, especificado y generado en busca de la garantía de condiciones de vida dignas para las personas y las comunidades, especialmente respecto de los grupos más vulnerables, que son quienes en mayor medida sufren la falta de un suministro apropiado de agua en cantidad y calidad suficientes para su bienestar, porque aunque "el derecho al agua no es más que un hecho natural y social, consecuencia de la necesidad de este elemento para vivir" (García, 2008, p. 19), pareciera que la tendencia es a considerar el agua como un bien económico susceptible de ser objeto del mercado y no como un bien público y social cuyo acceso es en sí mismo un derecho humano.

Por ello se reafirma que el derecho humano al acceso al agua potable es una forma de abonar a la tutela de la dignidad humana, pues como bien lo plantea Eusebio Fernández (2001),

[...] muchas referencias a las exigencias de la dignidad humana, si queremos darle contenido, reclamarán el de los derechos humanos fundamentales ya que estos han de verse como su medio de protección, es decir, como condiciones inexcusables de una vida digna (p. 20).

Al respecto, cabe mencionar los siguientes datos en relación con las necesidades básicas de supervivencia, salud, bienestar y seguridad que satisface el acceso suficiente en calidad y cantidad al agua potable, así como las amenazas que su ausencia de garantía representa en contra de la dignidad de las personas en el escenario actual: 
1. El agua es un elemento indispensable para preservar la salud y la vida. Diariamente mueren 4.500 niños en el planeta debido a la falta de acceso a sistemas adecuados de saneamiento (Ki-moon, 2013), por lo que el agua se convirtió en el arma de destrucción masiva más letal de la historia (Arrojo, 2006: pág. 108). La Corte Interamericana de Derechos Humanos (CIDH) (Caso Instituto de Reeducación del Menor us. Paraguay, 2013) determinó como parte del derecho a la vida, la obligación que tienen los Estados de garantizar la supervivencia, y el agua es esencial para tal efecto, por ser imprescindible para la vida; sin agua el ser humano no tiene probabilidades de sobrevivir (párr. 161).

A través del caso Comunidad Indígena Xákmok Kásek vs. Paraguay (CIDH, 2010), dicha jurisdicción declaró que cuando un Estado es omiso en suministrar agua suficiente en cantidad y calidad para preservar la salud, deja a las personas en una situación de riesgo especial, real e inmediato que atenta contra sus condiciones de vida digna; configurándose así una violación al artículo 4.1 de la Convención Americana sobre Derechos Humanos (CADH) que establece el derecho de toda persona a que su vida sea respetada, en relación con su artículo 1.1, que dispone la obligación de los Estados parte de respetar y garantizar los derechos y las libertades consagradas en la Convención, y su libre y pleno ejercicio sin discriminación alguna a quienes se encuentren sujetos a su jurisdicción (párr. 217).

2. Del acceso al agua potable en el domicilio o sus cercanías depende que la persona goce de una vivienda digna. El Comité de Derechos Económicos, Sociales y Culturales (CDESC, 1991) indicó que una vivienda adecuada debe tener acceso permanente a los servicios indispensables para la salud, la seguridad, la comodidad y la nutrición, como son: el abastecimiento de agua potable $e$ instalaciones sanitarias de eliminación de desechos y drenaje (párr. 8, inciso b).
3. En los últimos años, el agua ha sido tratada como un detonador de conflictos entre naciones y comunidades. Es un recurso escaso y la demanda es creciente; sin embargo, los países que compiten entre sí por acceder a él han respondido mediante la cooperación para evitar conflictos. El $40 \%$ de la población mundial vive en una de las 263 cuencas comunes a dos o más países, entre los cuales se han logrado pactar más de 300 acuerdos internacionales en la materia, aun cuando no han podido arreglar entre sí otro tipo de diferencias (Ki-moon, 2009).

No obstante, los conflictos por el agua no dejan de ser un riesgo latente, pues existen regiones en las que los acuerdos no han sido posibles y las comunidades están sufriendo día a día la guerra por el líquido. Debido a su escasez como un recurso esencial para la supervivencia, comunidades enteras se desplazan en busca de lugares con mejores condiciones de disponibilidad y acceso; dicho intento conlleva enfrentamientos con otros grupos para competir por el recurso básico $y$ escaso poniendo en riesgo su seguridad y su integridad física.

4. El agua potable es materia prima esencial para la obtención de alimentos y es, en sí misma, un alimento primordial para la supervivencia. La agricultura es la primera fuente de alimentos en el mundo, y es también la actividad productiva que mayor cantidad de agua demanda, por lo que la producción de alimentos depende, en primer lugar, de su disponibilidad. Si no hay agua no hay cosechas ni alimentos.

Existe una conexión entre la seguridad hídrica y la seguridad alimentaria y nutricional: la población mundial está en constante crecimiento, por lo que el incremento en la producción de alimentos para satisfacer las necesidades alimentarias y nutricionales del cada vez más alto número de personas en el planeta implica mayor demanda de agua. La agricultura es el principal destino del agua dulce en la Tierra, por lo que si no se comienza a utilizar de manera más sensata, persistirán la 
sequía, la hambruna y la inestabilidad política. La escasez del vital líquido ha generado ya en varios lugares la disminución de la producción agrícola, lo que agrava los riesgos y la imprevisibilidad en la situación de las personas que se dedican a dicha actividad (Ki-moon, 2012). Incluso, el CDESC (2003) ha hecho hincapié en la relación del derecho al agua con el derecho a la alimentación, especialmente por la importancia de garantizar a los agricultores en condiciones menos beneficiosas, y en particular a las mujeres, un acceso sostenible y equitativo a ella y a sus sistemas de gestión para la ejecución de la agricultura de subsistencia (párr. 7).

Como hemos visto, el agua es primordial para que las personas y los pueblos vivan y se desarrollen plena y dignamente al favorecer las condiciones de alimentación, salud y vivienda; sin acceso a ella, no podremos sobrevivir, peligra nuestra vida y nuestra salud; en la competencia por su acceso peligraría nuestra seguridad; ni hablar de la posibilidad del ejercicio de otras libertades o la satisfacción de otras necesidades cuando la supervivencia, la salud y la seguridad no están garantizadas.

Una vez abordada la justificación del acceso al agua potable como un asunto de dignidad desde el ámbito teórico, es decir, en razón de ser un satisfactor indispensable a las necesidades humanas, pasaremos ahora, por los mismos motivos que se citan respecto del concepto de dignidad a su positivización en líneas anteriores: de la justificación del agua como un asunto de dignidad al reconocimiento de dicha situación en el ordenamiento jurídico y constitucional de los Estados, por ser este uno de los elementos necesarios para eliminar la brecha entre la teoría de su configuración como derecho humano y su efectivización, pues dicho medio facilita su exigibilidad. En ese sentido, menciona García (2008) que resulta indispensable la intervención correctiva del derecho, ya que "por tratarse no solo de una necesidad, sino de una necesidad básica amenazada, esta juridificación debe realizarse en clave de derechos" (p. 51).
Para ello, consideramos pertinente hacer referencia a la Constitución Política de Bolivia como ejemplo de máximo ordenamiento jurídico que reconoce expresamente en la dignidad humana, el fundamento y fin del derecho humano al acceso al agua potable; así como la trascendencia que este hecho tiene en el cumplimiento del derecho y en la calidad de vida de los individuos y las comunidades.

De tal manera que, según la propuesta de Rolla (2002) de la dignidad humana como principio constitucional de interpretación aplicable a todos los derechos, esta Constitución posibilita la interpretación progresiva y evolutiva del derecho humano al acceso al agua potable y con ello la optimización de su contenido y alcances, al valorar la dignidad humana como el bien jurídico específico tutelado por él. Tal Constitución prevé en el tercer párrafo de su preámbulo, el acceso al agua como una condición esencial para la dignidad humana, para el "vivir bien", como a continuación se cita:

Un Estado basado en el respeto e igualdad entre todos, con principios de soberanía, dignidad, complementariedad, solidaridad, armonía y equidad en la distribución y redistribución del producto social, donde predomine la búsqueda del vivir bien; con respeto a la pluralidad económica, social, jurídica, política y cultural de los habitantes de esta tierra; en convivencia colectiva con acceso al agua, trabajo, educación, salud y vivienda para todos (énfasis fuera de texto).

El carácter social plasmado en el preámbulo de esta Constitución supone la dignidad, la solidaridad y la equidad como pilares fundamentales para la consecución del objetivo primordial del Estado: el cumplimiento de los derechos humanos y su especificación en relación con distintos grupos y personas debido a las circunstancias de vulnerabilidad en las que se encuentran; en particular en lo que atañe a las barreras a las que se enfrentan para acceder en condiciones de igualdad y sin discriminación a los bienes y servicios cuyo acceso es condición para el 
bienestar, como lo es el acceso al agua; viendo el origen de la necesidad y su satisfacción en la propia dignidad humana.

\section{B. El acceso al agua potable y el saneamiento: un derecho humano}

Como se planteó en el apartado anterior, la dignidad humana es el origen de todas aquellas necesidades de la persona para desarrollarse plena e integralmente, y podríamos decir que, en consecuencia, la satisfacción de dichas necesidades constituye, en sí misma, el ejercicio de los derechos humanos. Es decir, la estructuración, el contenido y la satisfacción del conjunto de necesidades originadas en la dignidad humana, conforman los derechos humanos.

Las personas, en su esfera individual, tienen como objetivo fundamental y universal la búsqueda de la felicidad, entendida esta como el pleno goce de los derechos humanos y el correlativo bienestar y condiciones de desarrollo que ello genera. En el ámbito colectivo, los pueblos aspiran al progreso económico y social, que no puede lograrse integralmente más que teniendo como base el cumplimiento de los derechos humanos (Asamblea General de las Naciones Unidas, 2011).

La felicidad, el bienestar y el progreso son manifestaciones del ejercicio y cumplimiento de los derechos humanos y deberían ser las directrices de las políticas de todo Gobierno. Incluso, la ONU (2012) sostiene que la felicidad debería ser el nuevo paradigma económico sostenido por los pilares de la paridad social y económica y la igualdad en el goce de los derechos ${ }^{2}$, pues

2 La Asamblea General de las Naciones Unidas proclamó el 28 de junio de 2012 a través de su resolución 66/281, el 20 de marzo de cada año como el Día Internacional de la Felicidad. Véase también: Asamblea General de las Naciones Unidas. (28 de junio de 2012). Resolución 66/281. Día Internacional de la Felicidad. Recuperado el 23 de agosto de 2013, de http://www.un.org/es/comun/docs/?symbol=A/ RES/66/281//Véase también: Organización de las Naciones Unidas. (s.f.). La búsqueda de la felicidad es una meta fundamental. Recuperado el 23 de agosto de 2013, de http://www.un.org/es/events/happinessday/ estos constituyen en sí mismos el fundamento del Estado.

Así, la Declaración de los Derechos del Hombre y del Ciudadano (1789) disponía que el fin de toda asociación política era la conservación de los derechos naturales e imprescriptibles de las personas, siendo estos la libertad, la propiedad, la seguridad y la resistencia a la opresión (artículo 2). Entonces, la existencia del Estado se justifica cuando el ser humano deja su estado de naturaleza al pactar su sometimiento a una autoridad para que esta le garantice y tutele sus derechos, una autoridad que obedezca y atienda la voluntad general que demanda la protección de su dignidad individual y el ejercicio de sus libertades, "si no, ¿para qué queremos un Estado?" (Estrada, 2010, pp. 71-72).

Los derechos humanos son pues, derechos inherentes a la dignidad humana y, por lo tanto, a todas las personas; como parten del reconocimiento de la dignidad de todo sujeto suponen, además, la igualdad entre toda la especie. Todos los individuos poseen la misma dignidad y, por ende, los mismos derechos universales cuya existencia no depende de su reconocimiento y garantía por el orden jurídico o político de un cierto Estado.

Ferrajoli (2001) denomina derechos fundamentales a los derechos universales reconocidos y garantizados por una norma; sin embargo, hace énfasis en que la previsión del derecho en un sistema jurídico determinado, si bien es condición de su vigencia dentro del mismo, no lo es respecto de su existencia fuera de él. Es decir, que la imputación universal de los derechos fundamentales como un rasgo estructural de estos, que dota de un carácter inalienable a los intereses sustanciales que los mismos constituyen y, que coinciden con las libertades y necesidades de cuya garantía dependen la vida, la supervivencia, la igualdad y la dignidad de los seres humanos, es una condición previa e independiente de su positivización; no obstante, esta es la garantía de su observancia, pero no el derecho humano en sí (pág. 19-24). 
En ese mismo sentido, Peces-Barba (1999) señala que el reconocimiento jurídico de los derechos fundamentales como expresiones de la dignidad humana, basados en los principios de libertad, igualdad, seguridad y solidaridad, es la condición que les dota de exigibilidad, mas su existencia es previa; y que tanto los principios universales que estos constituyen, como la garantía de cumplimiento y exigibilidad que les proporciona su positivización, son los pilares del Estado social y democrático de derecho (págs. 109-112).

Tenemos entonces que los derechos humanos, universales e inalienables a la condición de dignidad humana, originados y fundamentados en ella, existen y demandan eficacia y cumplimiento, independientemente de su reconocimiento y garantía por el orden jurídico o político de un Estado determinado, pero dicha circunstancia es, sin duda, un factor que facilita su exigibilidad frente a terceros y frente al propio Estado.

Por ello se afirma que el acceso al agua potable y el saneamiento es un derecho humano por ser un satisfactor directo y esencial a todas las necesidades básicas de alimentación, supervivencia, salud, vivienda, desarrollo y bienestar que emanan de la dignidad humana; lo que conduce a la universalidad de su titularidad y pretensión, que se hace exigible a través de su reconocimiento en los sistemas jurídicos de los Estados. Circunstancia que, aunque no constituye integralmente su garantía sino únicamente un aspecto de ella, sí posibilita su cumplimiento por parte del Estado a través de la actuación de sus autoridades en un marco de legalidad. Aunque a dicha garantía jurídica de reconocimiento y tutela habría de sumarse, para la verdadera materialización del derecho, una garantía ética; es decir, el ánimo de los actores estatales para su realización porque, de no existir este, la positivización constitucional del derecho puede quedar tan solo en una declaración de buenas intenciones.

En esa misma dirección se pronuncia Víctor M. Sánchez (2008), al señalar que el derecho fundamental al acceso al agua potable tiene una significativa dimensión ética, moral y política; pues aunque el reconocimiento de la dignidad humana y el conjunto de necesidades que de ella emana y demanda satisfacción mediante dicho derecho, sea ya una conquista, su cumplimiento puede quedar en el limbo de las buenas intenciones cuando se carece de un marco normativo e institucional efectivo (pág. 13).

La Declaración Europea por una Nueva Cultura del Agua (2005) sugiere algunos criterios éticos a los Estados para el establecimiento de la garantía del derecho y la protección del recurso hídrico en cuanto a sus usos, gestión y distribución, por tratarse de un bien que es objeto de un derecho humano. Estos aspectos éticos son retomados por Arrojo (2006: págs. 103-106), quien al plantearse qué es el agua en términos jurídicos, concluye que eso depende de los valores que las personas y el Estado pongan en juego para determinar los usos y funciones que priorizarán para el destino del agua, mismos que se categorizan por la citada Declaración de la siguiente manera:

Agua-Vida, es decir "agua para la vida", en su función prioritaria para la supervivencia de todos los seres vivos, incluidos los humanos, para quienes su acceso a cuotas básicas es un derecho humano. Agua-Ciudadanía, entendido el término ciudadanía como toda la sociedad, puesto que comprende su función de elemento en las actividades de interés general, como la prestación de los servicios públicos de agua potable y saneamiento, cuyo nivel de primacía sigue al Agua-Vida.

En tercer orden de preponderancia está el AguaNegocio, que comprende el agua para el crecimiento económico, esto es, cuando se utiliza en actividades económicas lícitas, actividades productivas ejercidas en relación con el derecho a mejorar el nivel de vida. Esta prioridad no puede ser antepuesta de ninguna manera a las dos anteriores y poner en riesgo los derechos que estas garantizan. Finalmente, tenemos la categoría del Agua-Delito, que es la empleada para fines ilícitos en procesos productivos que ponen en riesgo la salud y los ecosistemas, que deben ser evitados 
y perseguidos; por ejemplo, la sobreexplotación o contaminación de los recursos naturales.

A partir de estas consideraciones éticas en cuanto al derecho, en el sentido de que su positivización en el ámbito jurídico estatal no es suficiente para su garantía y que dicha garantía debe complementarse en la práctica con una garantía ética por parte del poder público, es que Arrojo (2006) concluye que la realización del derecho humano al agua "tal vez se trate de un problema ético", ya que las prioridades de usos y funciones del agua se relativizan según intereses económicos, sin importar las afectaciones a la salud de comunidades enteras y la insostenibilidad de los ecosistemas, o la necesidad que tengan los sectores más vulnerables de la población de contar con acceso a ella, y así a condiciones dignas de vida (pág. 106).

\section{El acceso al agua potable y el saneamiento: un derecho social}

Bobbio (citado en Peces-Barba, 2004) menciona que los derechos nacen cuando deben o pueden hacerlo, cuando el progreso o el poder amenazan la dignidad y las libertades de la persona; como límites al poder para impedir daños a su dignidad o como beneficios del poder para allegarse de bienes y servicios básicos para la subsistencia. A esto, Peces-Barba (2004) añade que los derechos humanos, además de constituirse como límites al poder o para obtener beneficios de él, emergen como medios de acceso al mismo reservado hasta entonces a una minoría; y no únicamente al poder político, sino además al económico; esto es, el acceso a los bienes y los servicios que procuran el bienestar integral de las personas $y$ cuya escasez complica la generalización de su ejercicio. De ahí que la función del Estado sea repartir entre todos, con justicia y equidad, los bienes que no todos alcanzarían a través de las leyes del mercado (págs. 129-134), entre ellos: el agua.

El cumplimiento de los derechos sociales en su conjunto comprende entonces el acceso a los bienes imprescindibles para la satisfacción de las necesidades más básicas del ser humano para tener una vida digna, como son: el vestido, la alimentación, la salud, la vivienda, el ingreso y la educación. Pisarello (2003: pág. 23) los llama los "derechos de los desaventajados", porque son los sujetos y los grupos más vulnerables de la sociedad, quienes tienen mayormente restringido el acceso a dichas prestaciones siendo, por lo tanto, los más interesados en su exigencia.

Riveros (2010) menciona que estos derechos económicos y sociales tienen un carácter prestacional, su cumplimiento tiene que ver con prestaciones a cargo del Estado para su materialización; "la característica distintiva para identificar estos derechos es su connotación prestacional. Los derechos sociales implican el nacimiento de obligaciones positivas para cuya realización es necesario un dar o hacer por parte del Estado" (págs. 38-39); por ejemplo, la prestación de los servicios de abastecimiento de agua potable, drenaje, alcantarillado, tratamiento y disposición de aguas residuales, que posibilitan a las personas y las comunidades, el acceso a un suministro continuo de agua en la cantidad y la calidad suficientes para preservar la salud, un entorno adecuado, el desarrollo y, en general, condiciones para una vida digna.

El proceso para el reconocimiento jurídico y el respeto político de los derechos sociales a través de su constitucionalización y los paradigmas establecidos por el Estado social de derecho, se ha desarrollado: por una parte, sí contribuyendo a la configuración de una verdadera democracia a través de la constitucionalización de los derechos sociales, favoreciendo a los grupos más vulnerables en su ejercicio y su exigibilidad; pero, por otra parte, mediante prestaciones concedidas a modo de intervenciones mínimas de asistencia, inspiradas más en la caridad que en la igualdad social, conformando así nuevos sistemas de sometimiento por medio de regímenes clientelistas o paternalistas. De igual manera se han establecido objetivamente modelos económicos de desarrollo que benefician en primera instancia a los intereses del sector privado; contexto en el cual algunos recursos, como el agua por ejemplo, 
han sido considerados objeto de una explotación casi ilimitada, tanto por los sectores públicos como privados, lo cual vulnera los derechos sociales, ya sea por la comisión de delitos y daños ecológicos o, porque el mercado condiciona su acceso a prácticas discriminatorias (Pisarello, 2003: págs. 25-29).

En el Estado social de derecho, el individuo cede el ámbito de su autonomía al Estado para que este le garantice derechos y prestaciones sociales efectivas. El constitucionalismo social, además de establecer libertades para los individuos, impone al Estado como primera obligación, la garantía de los derechos; para cuyo cumplimiento, las decisiones relativas a los recursos, su empleo, distribución y destino prioritario, pasarán del ámbito de la discrecionalidad política, al ámbito del derecho; de manera que el Estado ya no puede gastar el dinero público como mejor le parezca, sino según lo que la Constitución señale como prioridades y para la protección de los bienes esenciales. La naturaleza gratuita de los derechos sociales implica que las erogaciones necesarias para su concreción estarán a cargo del Estado, que cubrirá el costo que le generan vía impositiva. Ahí la justificación del Estado para imponer a los ciudadanos la obligación de pagar contribuciones: para allegarse de los recursos que le permitirán satisfacer las necesidades básicas de la población y así lograr una mejor distribución de la riqueza. Los derechos sociales son entonces tareas a cargo de los poderes públicos que han de realizarse de la mejor forma posible y considerando objetivamente los recursos disponibles (Böckenförde citado en Carbonell, 2011: págs. 41-43).

Resulta entonces indispensable para la efectividad de los derechos humanos, y particularmente de los derechos sociales, la integración de una perspectiva de derechos humanos, tanto en el presupuesto como en las políticas públicas, para que estos sean instrumentos idóneos en la realización de dicho fin, de la manera más racional y eficiente posible, según lo permitan los recursos disponibles y para beneficio de la mayor cantidad de población.
Ferrajoli (2002) hace el siguiente comentario en relación con la generalidad de los derechos humanos, cuya aplicación e interpretación específica a los derechos económicos y sociales resultan oportunas para enfatizar la obligación que el Estado tiene de proporcionarlos gratuitamente a la población para la subsistencia. Menciona dicho autor que: los derechos no son alienables ni negociables, corresponden a prerrogativas inalterables de sus titulares y son infranqueables para todos los poderes públicos y privados (pág. 39).

Por lo que en particular su tutela y efectividad no debe estar sujeta a ninguna otra condición que no sea la sola condición humana, su ejercicio no puede estar supeditado a las posibilidades económicas de las personas para pagar por los servicios públicos que los materializan, pues la obligación del Estado es con todos, en especial con los más vulnerables. La prestación de los servicios que traen a la realidad el cumplimiento de los derechos no puede estar sujeta a regateos ni permutas, porque ella constituye en sí la posibilidad de una vida digna, y su realización es, además, una obligación irrenunciable del Estado, pues constituye el fin y justificación de su existencia. Su cumplimiento compete a todo el aparato estatal, en todos sus niveles y a través de todas sus funciones; además, es el Estado quien debe ocuparse de la vigilancia de su cumplimiento, incluso entre los particulares y por los particulares.

\section{Fundamento internacional del derecho humano al agua}

El reconocimiento explícito del derecho humano al acceso al agua potable y el saneamiento es relativamente reciente como un derecho independiente, es decir, no asumiendo su existencia en función de su supuesto de cumplimiento como requisito para el cumplimiento de otro derecho; sino como un derecho individual. Fue en el 2010 cuando la ONU, en su resolución A/ $\mathrm{RES} / 64 / 292$, "reconoce que el derecho al agua potable y el saneamiento es un derecho humano esencial para el pleno disfrute de la vida y de 
todos los derechos humanos" (pág. 3, punto 1), por lo que insta, tanto a los Estados como a las organizaciones internacionales, para que a través de la cooperación proporcionen recursos financieros, capacitación y tecnología, especialmente a los países en desarrollo, para procurar el acceso al agua potable y el saneamiento a la población mundial (punto 2).

No obstante, este derecho ya había sido tratado implícita y explícitamente en distintos mecanismos internacionales, y plasmado en diversas resoluciones, declaraciones, informes y programas que resultaron de múltiples cumbres y conferencias mundiales; instrumentos que se mencionan en la resolución en cuestión como precedentes del derecho, entre los que se encuentran: la Conferencia Internacional sobre Agua y Desarrollo Sostenible, también conocida como la Conferencia de Dublín de 1992; la Conferencia de las Naciones Unidas sobre el Medio Ambiente y el Desarrollo o Cumbre de Río 1992, en el capítulo 18 del programa; la Conferencia Internacional de las Naciones Unidas sobre la Población y el Desarrollo de 1994; el programa Hábitat de 1996; la resolución 54/175 de la Asamblea General de las Naciones Unidas de 1999, relativa al derecho al desarrollo; la resolución 55/196 de la Asamblea General de las Naciones Unidas de 2000, que proclamó 2003 como Año Internacional del Agua Dulce; la Cumbre Mundial sobre el Desarrollo Sostenible de 2002; la resolución 58/217 de la Asamblea General de las Naciones Unidas en 2003, que declaró el Decenio Internacional para la Acción "El agua, fuente de vida"; la resolución 59/228 de la Asamblea General de las Naciones Unidas de 2004; el proyecto de directrices para la realización del derecho al agua potable y al saneamiento E/CN.4/Sub.2/2005/25, contenido en el informe del relator especial para el Consejo Económico y Social de las Naciones Unidas en 2005; y la decisión 2/104 del Consejo de Derechos Humanos sobre los derechos humanos y el acceso al agua de 2006.

También la resolución 61/192 de la Asamblea General de las Naciones Unidas de 2006, que proclamó el 2008 como Año Internacional del
Saneamiento; el Informe del Alto Comisionado de las Naciones Unidas para los Derechos Humanos sobre el alcance y los contenidos de las obligaciones pertinentes en materia de derechos humanos relacionados con el acceso equitativo al agua potable y el saneamiento, que imponen los instrumentos internacionales de derechos humanos en 2007; la resolución 7/22 del Consejo de Derechos Humanos de 2008, en la que se nombra a un experto independiente sobre la cuestión de las obligaciones de derechos humanos vinculadas con el acceso al agua potable y el saneamiento; la resolución 12/8 del Consejo de Derechos Humanos de 2009 y la resolución 64/198 de la Asamblea General de las Naciones Unidas de 2009, relativa al examen de mitad de periodo de las actividades del Decenio Internacional para la Acción "El agua, fuente de vida".

Como se puede observar, el contenido y alcances del derecho humano al acceso al agua potable y el saneamiento siguen especificándose a través de diversos instrumentos; sin embargo, cabe decir que el proceso de evolución de este derecho ha sido inverso al de generalización y posterior especificación de los derechos para la protección de las personas y grupos en situación de vulnerabilidad, pues el acceso al agua potable había sido previsto inicialmente en estos instrumentos específicos de protección, previo a su imputación universal como un derecho por sí mismo, ejemplo de ello son: la Convención sobre la Eliminación de Todas las Formas de Discriminación contra la Mujer (ONU, 1979), que dispone que el abastecimiento de agua es uno de los elementos ineludibles para el disfrute del derecho de las mujeres a desarrollarse en condiciones de vida dignas y adecuadas; indispensable además para asegurar su participación en el desarrollo y sus beneficios en condiciones de igualdad con el hombre.

Por lo que es obligación del Estado tutelar su acceso especialmente a aquellas mujeres que habitan en zonas rurales, como medida necesaria para eliminar su discriminación (art. 14, párr. 2 , inciso h). La Convención sobre los Derechos del Niño (ONU, 1989), que exige a los Estados parte combatir las enfermedades y la malnutri- 
ción, entre otras cosas, mediante el suministro de agua potable (art. 24, párr. 2, inciso c). La Observación General Número 6 (CDESC, 1995), relativa a los derechos de las personas mayores, que señala que la independencia de las personas de edad avanzada incluye, el acceso al agua, al decir textualmente que: "la independencia incluye el acceso a un alojamiento adecuado, comida, agua, vestido y atención a la salud" (párr. 5).

La Convención sobre los Derechos de las Personas con Discapacidad (ONU, 2006), que reconoce a las personas con discapacidad el derecho a un nivel de vida adecuado, en el cual progresivamente vayan mejorando sus condiciones de vida; para lo cual los Estados, entre otras cosas, deberán asegurarles, en condiciones de igualdad, el acceso al agua potable a precios asequibles para atender las necesidades derivadas de su situación (art. 28). La Observación General 15. El derecho al agua -artículos 11 y 12 del Pacto Internacional de Derechos Económicos, Sociales y Culturales (PIDESC) - (CDESC, 2002), considera como fundamento jurídico original internacional del reconocimiento del derecho humano al acceso al agua potable y el saneamiento, el artículo 11, párrafo primero del PIDESC, que establece:

Los Estados Partes en el presente Pacto reconocen el derecho de toda persona a un nivel de vida adecuado para sí y su familia, incluso alimentación, vestido y vivienda adecuados, y a una mejora continua de las condiciones de existencia.

La interpretación que el CDESC ha dado a través de la Observación General 15 a este artículo, es que la palabra "incluso" indica que la enunciación dada de los derechos indispensables para la realización del derecho a un nivel de vida adecuado no es exhaustiva, sino que deja espacio en dicha categoría a otros derechos necesarios para su cumplimiento, entre ellos, sin duda alguna, el derecho humano al acceso al agua por ser su ejercicio una condición fundamental para la supervivencia y, por ende, un derecho indispensable para asegurar un nivel de vida adecuado.
Así, en el escenario internacional encontramos el derecho humano al agua en documentos que tienen relevancia jurídica y vinculatoria internacional, pero no menos importante es su reconocimiento en otros instrumentos que sirven de mandatos éticos o morales, como son las declaraciones que orientan y redireccionan a los entes nacionales para actuar en consecuencia a favor de su materialización en sedes locales. Por ello, no existe duda de su existencia más allá de las fronteras de los Estados.

\section{E. Contenido del derecho humano al agua}

El CDESC (2003) definió el derecho humano al agua como el derecho de todos a disponer de agua suficiente, salubre, aceptable, accesible y asequible para el uso personal y doméstico, lo cual implica únicamente el acceso al agua necesaria para la satisfacción de las necesidades básicas del ser humano, para mantener la vida y la salud; no así, el derecho a disponer de una cantidad ilimitada de agua (Oficina del Alto Comisionado de las Naciones Unidas para los Derechos Humanos-OACNUDH-, 2011: pág. 9).

El derecho humano al acceso al agua potable y el saneamiento comprende, de manera general, las siguientes libertades y derechos: el acceso a un suministro suficiente de agua libre de injerencias, como por ejemplo, cortes arbitrarios; la no contaminación de los recursos hídricos; un sistema de abastecimiento y gestión que proporcione el acceso al agua a toda la población en igualdad de oportunidades; y una gestión sostenible que garantice el ejercicio del derecho para generaciones presentes y futuras (CDESC, 2003: párrs. 10-11).

El desglose de las anteriores prerrogativas implica, a su vez, los siguientes factores para el cumplimiento del derecho humano al agua: cantidad, calidad y accesibilidad.

Cantidad. Como ya lo hemos mencionado, el derecho humano al agua no implica la disponibilidad de una cantidad ilimitada del recurso, sino 
únicamente el acceso a un suministro suficiente para la satisfacción de las necesidades básicas de consumo personal y doméstico, el cual según el CDESC (2003: párr.12 a), incluye los siguientes usos: (i) consumo: agua destinada para bebidas y alimentos; (ii) saneamiento: agua necesaria para el funcionamiento de los sistemas de evacuación de excretas humanas; (iii) preparación de alimentos: agua utilizada para la higiene de los alimentos y su preparación; (iv) higiene personal y doméstica: agua empleada en el aseo del hogar y personal, incluso el lavado de ropa.

Es importante resaltar que otros tipos de usos que se pueden suscitar en el ámbito doméstico, como lo son las piscinas, la jardinería o el lavado de vehículos, no están amparados por el derecho humano al agua ${ }^{3}$, porque no son usos indispensables para mantener la vida o la salud de las personas, sino complementarios, por tratarse de necesidades secundarias de las cuales no dependen la supervivencia ni la dignidad humana.

Dicho lo anterior y una vez señalados los usos y destinos que deben ser garantizados a través del cumplimiento del derecho humano al acceso al agua potable y el saneamiento, pasemos a la cantidad de agua requerida por persona al día para la satisfacción de las necesidades que integran dichos usos. La Organización Mundial de la Salud (2006) indicó que cada persona necesita entre cincuenta y cien litros diarios de agua para cubrir sus necesidades básicas y evitar problemas de salud; sin embargo, un suministro mínimo diario que oscile entre los 20 y 25 litros puede permitir al ser humano sobrevivir (Howard \& Bartram, 2003: pág. 22); aunque claro está, altamente expuesto al padecimiento de problemas

3 En países africanos donde el agua es un recurso muy escaso, encontramos los siguientes ejemplos de legislación nacional que priorizan el uso del agua para la satisfacción de las necesidades de consumo personal y doméstico, incluso, prohibiendo algunos de ellos, cualquier otro tipo de usos en temporadas de sequías: Código del Agua de Benin; la Ley $\mathrm{N}^{\circ}$ 016/PR que regula los recursos hídricos en El Chad; el artículo 85 de la Ley $N^{\circ} 10-95$ sobre los recursos hídricos de Marruecos; el artículo 9 de la Ley $\mathrm{N}^{\circ}$ 98-041 relativa al agua del Niger; y el artículo 5 de la Ley de servicios de abastecimiento de agua de Sudáfrica. sanitarios por no contar con el agua suficiente para higiene y consumo, situación que no le permite vivir dignamente y por lo cual, esta cantidad mínima no constituye un parámetro para el cumplimiento del derecho; puesto que si bien es cierto, puede ser suficiente para mantener la vida, no así la salud ni las condiciones que facilitan a la persona desarrollarse en un entorno digno.

En cambio, el parámetro de requerimiento de cincuenta a cien litros diarios por persona sí es un indicativo para el cumplimiento del derecho, ya que además de preservar la vida, alcanza para que la persona se desarrolle en las condiciones mínimas de salud y dignidad. Aun así, hay personas o grupos que por motivos de salud, trabajo, condiciones climáticas u otros factores, necesitan de un mayor abastecimiento de agua, tal es el caso de mujeres embarazadas o en periodo de lactancia y personas que padecen alguna enfermedad. De tal manera que la cantidad mínima requerida por cada persona para el cumplimiento del derecho podrá exceder este parámetro indicativo según las circunstancias personales y el contexto en el que se desarrollan.

Calidad. "Son más las muertes atribuibles al agua contaminada que las causadas por todas las formas de violencia, incluida la guerra" (Ki-moon, 2010: párr. 3). El cumplimiento del derecho humano al agua tiene que ver, además de la cantidad de agua suministrada, con la calidad que esta posee. No basta con que las cantidades abastecidas sean suficientes volumétricamente para satisfacer el consumo personal y doméstico, se requiere también que el líquido sea potable, que no genere efectos nocivos en la salud de las personas, que sea apto para el consumo humano. Al respecto, el CDESC (2003) expresa que el agua debe ser salubre, de un olor, color y sabor admisibles, libre de microorganismos o sustancias químicas que amenacen la vida y la salud (párr. 12 b).

La mayoría de los problemas de salud se relacionan con el agua; la mitad de las camas de los hospitales en todo el mundo se encuentra ocupada por pacientes que padecen este tipo de 
enfermedades (Oficina del Alto Comisionado de las Naciones Unidas para los Derechos Humanos [OACNUDH], 2011: pág. 9). El contacto o consumo de agua contaminada por microorganismos como virus, bacterias y protozoos son la principal causa de enfermedades; los lactantes, los niños de corta edad, los adultos mayores, las personas debilitadas por alguna enfermedad o aquellas que viven en situaciones antihigiénicas son quienes más alto riesgo tienen de padecerlas.

Sin embargo, aunque tanto en países desarrollados como en desarrollo, los peligros microbianos son la principal razón de preocupación en relación con las enfermedades generadas por la contaminación del agua, existe otro tipo de contaminación que está generando un número creciente de personas enfermas por la mala calidad del agua, se trata de la contaminación suscitada por agentes químicos (OMS, 2006: págs. 11-12).

Accesibilidad. "El agua y los servicios e instalaciones de agua deben ser accesibles a todos de hecho y de derecho" (CDESC, 2003: párr. 12, inciso c, fracción III). Al definir el derecho humano al agua, mencionamos que básicamente este consiste en el acceso a un suministro suficiente en cantidad y calidad para preservar la vida y la salud. Como derecho humano es un derecho universal, un derecho para todos, un derecho que poseen las personas por su sola condición humana, sin discriminación alguna; de tal manera que el acceso al suministro de agua corresponde a todos. El aspecto de accesibilidad del derecho humano al agua se encuentra directamente asociado con la universalidad del mismo, es decir, con la no discriminación, con la accesibilidad que debe ser garantizada a todos los sujetos que integran la población de un Estado sin distinción alguna, a todos en igualdad de condiciones y oportunidades.

Los Estados tienen la obligación de garantizar, al igual que el ejercicio de todos los demás derechos sociales, el ejercicio del derecho al agua sin distinción alguna por motivos de raza, color, sexo, edad, idioma, religión, opinión, nacionalidad, posición económica o social, discapacidad física o mental, estado de salud, orientación sexual, estado civil o cualquier otra condición política, social o de otro tipo que pretenda o tenga por efecto anular o menoscabar el igual disfrute o el ejercicio del derecho al agua (PIDESC, 1966: arts. 2 y 3 ).

La distribución inequitativa del agua conduce a una discriminación que, aunque no sea manifiesta, existe. El CDESC (2003) trata el aspecto de accesibilidad del derecho como el hecho de que tanto el agua como las instalaciones y los servicios relacionados con ella sean accesibles para todos sin discriminación en las siguientes dimensiones (párr. 12, inciso c):

1. Accesibilidad física: el agua, las instalaciones y los servicios deben estar al alcance físico de toda la población. Cada hogar, ya sea vivienda permanente o alojamiento provisional; institución educativa o lugar de trabajo, debe contar con el acceso a un suministro de agua suficiente en cantidad y calidad para el consumo personal y doméstico. Si el acceso no se encuentra dentro de las instalaciones de estos, al menos debe ubicarse en sus cercanías inmediatas sin que la seguridad e integridad física de las personas se vean amenazadas en el trayecto.

2. Accesibilidad económica: "Ningún individuo o grupo debería verse privado del acceso a agua potable por no poder pagar" (OACNUDH, 2011: pág. 11). Los cargos y costos directos o indirectos generados por el abastecimiento de agua deben ser asequibles. El marco internacional de los derechos humanos no establece expresamente que el suministro de agua deba ser gratuito; aunque sí contempla que si la persona o la familia no pueden pagar los servicios de agua potable y saneamiento, estos les deberán ser proporcionados de forma gratuita en la medida de su suficiencia para preservar condiciones de vida digna. El Estado debe tutelar la satisfacción por lo menos de los niveles esenciales mínimos del derecho (OACNUDH, 2011: pág. 12). 
Al respecto, la Observación General 15 (CDESC, 2003: párr. 27), reitera la circunstancia de que la gratuidad no es una condición del cumplimiento del derecho generalizada, sino una opción para la ampliación de su cumplimiento y garantía, en especial a los grupos en situación de vulnerabilidad. La cuestión del costo pagado por el agua o los servicios que la acercan a las personas, tiene que ver más con criterios de equidad que de gratuidad, siendo esta una condición y obligación del Estado únicamente en el sentido de que no por que alguien no tenga los recursos económicos para pagar el servicio, se va a quedar sin él, en ese caso sí es obligación del Estado proporcionar el servicio de manera gratuita. El contenido del citado documento en este aspecto señala:

Para garantizar que el agua sea asequible, los Estados Partes deben adoptar las medidas necesarias, entre las que podrían figurar: a) la utilización de un conjunto de técnicas y tecnologías económicas apropiadas; b) políticas adecuadas en materia de precios, como el suministro de agua a título gratuito o a bajo costo; y c) suplementos de ingresos. Todos los pagos por servicios de suministro de agua deberán basarse en el principio de la equidad, a fin de asegurar que esos servicios, sean públicos o privados, estén al alcance de todos, incluidos los grupos socialmente desfavorecidos. La equidad exige que sobre los hogares más pobres no recaiga una carga desproporcionada de gastos de agua en comparación con los hogares más ricos.

El Programa de las Naciones Unidas para el Desarrollo propone que el precio que se ha de pagar por el servicio de agua potable y saneamiento no debe exceder el $3 \%$ del ingreso familiar (OACDH, 2011: pág. 11). En ese mismo sentido, el CDESC (2003) indica que la asequibilidad del derecho debe ser garantizada por los Estados a través de políticas de precios bajos o incluso a título gratuito. Atendiendo al principio de equidad, el precio por el servicio de agua, sea prestado por un ente público o por uno privado, deberá estar dentro de las posibilidades de pago de todos, especialmente de los grupos menos favorecidos (párr. 27).
No obstante, sucede que las personas con menor posibilidad de pago son las que más caro acaban sufragando el servicio, porque al no tener acceso a un suministro seguro de agua, tienen que comprársela a vendedores informales a un precio que excede entre el $20 \%$ y el $100 \%$ del que pagan las personas con mejores posibilidades económicas y que tienen acceso a agua corriente en sus domicilios mediante servicios municipales (Ki-moon, 2011). Peor aún es el caso de aquellos que en una situación más agravada de pobreza, no tienen dinero para conseguirla a través de vendedores informales y tienen que recabarla de ríos llenos de basura y altamente contaminados, exponiéndose a enfermedades por contacto o consumo de agua contaminada y que llegan a quedar imposibilitados para su aseo personal y doméstico, incluso, hasta para cocinar.

3. Acceso a la información: este aspecto comprende el derecho de las personas para solicitar, recibir y difundir información acerca de las cuestiones relativas al agua. En este sentido, el CDESC (2003) ha manifestado que todas las personas, individual o colectivamente, tienen el derecho de participar en los procesos de toma de decisiones que pudieran afectarles en el ejercicio del derecho humano al agua, debiendo proporcionárseles para tal efecto un acceso pleno a la información que esté en posesión de las autoridades públicas o de terceros respecto del recurso y su gestión. La participación popular sin discriminación alguna es uno de los principios para la formulación y ejecución de las estrategias y los planes nacionales de acción respecto al agua y debe ser parte integrante de toda política, programa o estrategia respecto de dicho recurso (párr. 48).

Lo expresado es relevante para materializar el derecho humano al acceso al agua potable, pues por un lado tenemos que considerar el conjunto de libertades y derechos que le den contenido, y por otro, la inclusión de las citadas prerrogativas de cantidad, calidad y accesibilidad, ya que al no actualizarse todos estos aspectos, sería insuficiente su cumplimiento. 


\section{F. Aproximaciones a la constitucio- nalización del derecho humano al agua en Latinoamérica}

Derivado del estudio comparado de diversas constituciones en Latinoamérica por lo que trata al reconocimiento, regulación y garantía del derecho humano al acceso al agua, son de resaltarse los siguientes ordenamientos, debido a que contienen amplios criterios jurídicos para su regulación y exigibilidad en favor de los gobernados:

1. La Constitución de Colombia ${ }^{4}$ por ejemplo, llega al punto incluso de limitar a sus entidades para que no destinen el excedente de sus recursos a otros rubros, en tanto no garanticen primero la prestación universal y calificada de los servicios públicos que hacen de los derechos sociales una realidad palpable a la población, entre ellos el servicio público domiciliario de agua potable y saneamiento.

Hablamos de una Constitución de carácter eminentemente social que hace hincapié en reiteradas ocasiones en la obligación que tiene el Estado de atender preferentemente a los sectores más vulnerables. En ese mismo sentido, esta Constitución establece que serán estos los principales beneficiarios en los planes y presupuestos destinados a la ampliación de la cobertura de los servicios públicos que les permiten ejercer sus derechos sociales, entre ellos el servicio público domiciliario de agua potable y saneamiento. En general, el máximo cuerpo normativo colombiano regula el servicio público de agua potable y saneamiento, así como la distribución de los recursos para su prestación, siempre de conformidad con los principios de solidaridad y equidad.

Es de resaltarse, además, que la Carta Magna de Colombia tutela el ejercicio del derecho humano al agua y el saneamiento en su más alto nivel,

$4 \quad$ El detalle de cada una de las disposiciones constitucionales relativas al derecho humano al agua, su reconocimiento y garantía en el Estado de Colombia pueden consultarse en los artículos 356 inciso a; 357 y 366. pues atribuye al servicio público de agua potable y saneamiento la característica de ser domiciliario, que es la máxima expresión de accesibilidad física al recurso y, por lo tanto, el mejor nivel de ejercicio del derecho al permitir un suministro continuo a través de grifos en cada vivienda, es decir, un acceso óptimo para la satisfacción del derecho, de las necesidades básicas de consumo personal y doméstico que incluyen higiene personal, de alimentos y casa, lavandería y baño.

2. La Constitución de Ecuador $^{5}$, que considera el agua un bien nacional público, inalienable, imprescriptible, inembargable y estratégico debido a sus implicaciones económicas, sociales, políticas y ambientales; por lo que prohíbe toda forma de privatización, siendo facultades exclusivas del Estado su administración, regulación, control y gestión para el pleno desarrollo de los derechos y el interés social de acuerdo con los principios de sostenibilidad, precaución, prevención y eficiencia.

La Constitución de Ecuador prioriza el destino de los recursos hídricos para el consumo humano, y después, en este orden, para el riego que garantice la soberanía alimentaria, el caudal ecológico y finalmente para las actividades productivas. Es importante destacar en este último aspecto, que cualquier aprovechamiento del agua con fines productivos, ya sea por parte del sector público o del sector privado, requerirá autorización del Estado.

En lo relativo al servicio público de agua potable, está previsto constitucionalmente que incluya riego y saneamiento, alcantarillado y depuración de aguas residuales; todos ellos son considerados servicios sociales necesarios y su prestación compete al municipio, siendo únicamente personas

5 En cuanto al contenido de la Constitución de Ecuador, relativo al reconocimiento del derecho humano al agua, su protección, garantía y relación con otros derechos, así como la gestión, administración y cuidado de los recursos hídricos y la prestación del servicio público que materializa el derecho, consúltense: artículo 3, fracción I; $12,15,32,66$, fracción $2 ; 264$, fracción 4; 276, fracción 4; 281, fracción 4; 282; 313, 314, 318, 326, fracción 15; 375, fracción 6; 411, 413, 415, 419, fracción 8; 423, fracción 2 y disposición transitoria vigésimo sexta. 
jurídicas estatales o comunitarias las que pueden efectuarlo. La paralización o suspensión de estos servicios está prohibida aun cuando se haga en razón del reclamo a los principios que sustentan el derecho al trabajo.

Esta Constitución determina incluso en una de sus disposiciones transitorias, la condonación de las deudas de agua para el consumo humano a los usuarios en situación de extrema pobreza, que hayan sido contraídas previamente a 2008, año en que entró en vigor la Constitución en comento.

En su relación con el derecho humano a la alimentación, por ejemplo, la Carta Política de Ecuador impone al Estado la obligación de promover las políticas que posibiliten al campesino el acceso al agua como recurso productivo para lograr la soberanía alimentaria, que es, además, un objetivo estratégico. Así mismo, se impone al Estado la obligación de regular el agua para riego y producción de alimentos bajo los principios de equidad, eficiencia y sostenibilidad ambiental, prohibiéndose el acaparamiento o privatización del agua y sus fuentes.

En cuanto al nexo entre derecho humano al agua y derecho humano a una vivienda digna, la Constitución de Ecuador señala que garantizar la dotación ininterrumpida del servicio público de agua potable es una condición para el cumplimiento del derecho humano a una vivienda digna, contemplando incluso para tal efecto no únicamente los espacios en los cuales la estancia es permanente, sino también parcial, como escuelas y hospitales.

3. La Constitución de México (artículo $4^{\circ}$, sexto párrafo) reconoce el derecho al acceso, disposición y saneamiento de agua para consumo personal y doméstico, así como su garantía por parte del Estado y la concurrencia de los tres órdenes de Gobierno para que su acceso y uso sean equitativos y sustentables.

Además de dicho numeral, este máximo ordenamiento jurídico contiene otras disposiciones relativas al recurso ${ }^{6}$ en las que, entre otras cosas, se prevé que las aguas dentro del territorio mexicano son propiedad de la nación, quien tiene la facultad de transmitirla a los particulares por medio de concesiones para su uso y explotación, inclusive para la constitución de la propiedad privada, quedando dichas figuras sujetas en todo momento a las modalidades que dicte el interés público. Este derecho es exclusivo de los mexicanos, sin embargo, se prevé la posibilidad de que también los extranjeros puedan ser titulares si convienen con la Secretaría de Relaciones Exteriores en considerarse como nacionales respecto de tales bienes y renunciar a la protección de sus gobiernos para la defensa de los derechos que sobre ellos adquieran.

Se establece también en el ámbito constitucional que el aprovechamiento del agua sea siempre en beneficio social, encaminado a mejorar las condiciones de vida de las comunidades urbanas y rurales; para la distribución equitativa de la riqueza pública, la procuración del desarrollo del país y la conservación misma del recurso. Estos mismos objetivos habrán de perseguirse en toda obra pública en materia de agua y en todo ordenamiento de los asentamientos humanos, para asegurarles además la adecuada provisión, uso, reserva y destino de aguas.

4. La Constitución de la República Dominicana ${ }^{7}$ tiene un aspecto interesante, pues impone al Estado el cumplimiento de los derechos económicos y sociales de acuerdo con las pautas que marcan los instrumentos internacionales y los organismos por ellos facultados para su interpretación, dando prioridad en todo momento a los sectores económicamente más vulnerables de la población.

6 Las disposiciones jurídicas del orden constitucional mexicano que tratan sobre todo lo relativo al agua son los artículos 4, sexto párrafo; 27, fracciones I, VII, VIII incisos a), b) y c) y fracción XVIII; 42, fracciones I, II, III, IV, V y VI; 48, 73, fracciones XVII, XXIX núm. 2 y fracción XXIX-L; 107, fracción II párrafos 5 y 6, y 115 , fracción III inciso a) y fracción $V$ inciso i).

7 Los artículos 15 y 61, fracciones I y II de esta Constitución tratan específicamente lo relativo al agua. 
5. La Constitución de Uruguay 8 contempla, en lo que atañe al régimen de propiedad de las aguas, el recurso hídrico como un bien estatal de dominio público subordinado al interés general; y en lo relativo a la prestación del servicio público de saneamiento y abastecimiento de agua para consumo humano, queda fijado constitucionalmente como competencia exclusiva del Estado, por lo que las disposiciones concernientes al ingreso del capital privado, entes autónomos o servicios descentralizados no serán aplicables a los servicios públicos de agua potable y saneamiento.

Por otra parte, en el ámbito internacional, esta Constitución señala que podrá brindarse solidariamente a otro país falto de abasto, un suministro de agua sólo si tres quintas partes de cada cámara votan a favor.

6. De la Constitución de Venezuela ${ }^{9}$ cabe resaltar que la legislación y las políticas en materia de aguas son competencia exclusiva del poder público nacional; y para el fomento y aprovechamiento del recurso se harán asignaciones económicas especiales de ley a los Estados en cuyo territorio exista el recurso hídrico.

Así, en América Latina se presenta una tendencia clara hacia la constitucionalización del derecho humano al agua, pues las constituciones relativamente nuevas lo contemplan; pero no únicamente desde el punto de vista de su reconocimiento, sino que a la par construyen los medios para hacer posible su garantía por los operadores jurídicos nacionales. Tal circunstancia refuerza, sin lugar a dudas, el derecho que emana en sede internacional que en ocasiones adolece de técnicas de garantías efectivas en el orden local.

8 Las disposiciones constitucionales que señalan en concreto la regulación en torno al agua en Uruguay son los artículos 47, fracción I, incisos a), b), c) y d), fracciones II y III; 188 y 47, fracción IV.

9 Los artículos de la Constitución de Venezuela que establecen lo relativo al agua son: 127, 156, incisos 16, 23 y $29 ; 178$ y 304.

\section{Conclusiones}

Tanto la teoría como los instrumentos internacionales en materia de derechos humanos han aportado elementos que integran el conjunto de obligaciones que tienen los Estados para la realización del derecho humano al acceso al agua potable y el saneamiento. Estos elementos, todavía en configuración, incluso por los sistemas regionales de protección de los derechos, no constituyen objetivos ni metas utópicas o inalcanzables, pues el principio de progresividad de los derechos permite a los Estados, para su cumplimiento, la implementación paulatina y gradual de todas las acciones correspondientes encaminadas a dicho propósito. Además, como hemos visto, debido al principio de indivisibilidad $e$ interdependencia de los derechos, el progreso en el cumplimiento del derecho humano al acceso al agua potable y el saneamiento incide directamente en el goce de otros derechos sociales, procurando así a las personas un estado integral de bienestar y reflejando al mismo tiempo un avance significativo en la voluntad y el cumplimiento de las obligaciones del Estado para la eficacia general de los derechos fundamentales.

Una de las medidas adoptadas por los Estados para el cumplimiento del derecho ha sido su positivización mediante el camino de su constitucionalización, para facilitar su exigibilidad a través de garantías jurisdiccionales tanto en instancias nacionales como supranacionales; sin embargo, esta medida por sí sola no ha resultado suficiente, pues no se han adoptado por parte de los poderes públicos y privados las medidas éticas que repercutan en el ámbito administrativo para su cumplimiento y para llevar el derecho de la norma a la realidad, partiendo de la voluntad y disposición de todos los elementos individuales que integran y representan al Estado, tal como aparecen en los indicadores presentados en este trabajo.

No obstante, la difusión del derecho, su contenido y alcances, coadyuvan en la creación de una consciencia de respeto y ejercicio responsable, y se han 
logrado avances sustanciales en su tutela por parte de organismos jurisdiccionales y no jurisdiccionales en diferentes latitudes, incluyendo Latinoamérica. A pesar de estos avances, resulta evidente que falta todavía mucho camino por recorrer para alcanzar la efectiva materialización del derecho que demandan la dignidad de las personas y los pueblos en condiciones de igualdad para conseguir un desarrollo y progreso común y sustentable, a través de un sistema de garantías que priorice el uso de los bienes públicos para el cumplimiento de los derechos humanos y no como insumos en procesos productivos cuantificables en dinero y no traducidos en bienestar para las personas.

\section{Referencias}

Arrojo, P. (2006). El reto ético de la nueva cultura del agua. Funciones, valores y derechos en juego. Barcelona: Paidós.

Asamblea General de las Naciones Unidas. (16 de diciembre de 1966). Pacto Internacional de Derechos Económicos, Sociales y Culturales. Disponible en: http://www.ohchr.org/ SP/ProfessionalInterest/Pages/CESCR.aspx

Asamblea General de las Naciones Unidas. (1979). Convención sobre la eliminación de todas las formas de discriminación contra la mujer. Disponible en: http:// www.unicef.org/panama/spanish/MujeresCo_web.pdf

Asamblea General de las Naciones Unidas. (1989). Convención sobre los Derechos del Niño. Disponible en: http://www.ohchr.org/ SP/ProfessionalInterest/Pages/CRC.aspx

Asamblea General de las Naciones Unidas. (2006). Convención sobre los Derechos de las Personas con Discapacidad. Disponible en: http://www.un.org/esa/socdev/enable/ documents/tccconvs.pdf

Asamblea General de las Naciones Unidas. (3 de agosto de 2010). A RES 64/292. El derecho al agua y el saneamiento. Disponible en: http://www.un.org/es/comun/ docs/?symbol $=\mathrm{A} / \mathrm{RES} / 64 / 292$
Asamblea General de las Naciones Unidas. (25 de agosto de 2011). Resolución 65/309. La felicidad: hacia un enfoque holístico del desarrollo. Disponible en: http://www.un.org/ en/ga/search/view_doc.asp?symbol=A/ $\mathrm{RES} / 65 / 309 \&$ Lang $=\mathrm{S}$

Asamblea General de las Naciones Unidas. (28 de junio de 2012). Resolución 66/281. Día Internacional de la Felicidad. Disponible en: http://www.un.org/es/comun/ docs/?symbol=A/RES/66/281

Carbonell, M. (2011). Los derechos fundamentales en México ( $4^{\mathrm{a}}$ ed.). México D. F.: Porrúa.

Comité de Derechos Económicos, Sociales y Culturales. (1991). Observación general No. 4. El derecho a una vivienda adecuada. Ginebra: ONU. Disponible en: http:// conf-dts1.unog.ch/1\%20SPA/Tradutek/ Derechos_hum_Base/CESCR/00_1_obs grales_Cte $\% 20 \bar{D}$ chos $\% 20 \mathrm{Ec} \% 20 \overline{\mathrm{S}}$ oc $\% 2 \overline{0}$ Cult.html\#GEN4

Comité de Derechos Económicos, Sociales y Culturales. (1995). Observación general No. 6. Los derechos económicos, sociales y culturales de las personas mayores. Ginebra: ONU. Disponible en: http:// conf-dts1.unog.ch/1\%20SPA/Tradutek/ Derechos_hum Base/CESCR/00_1_obs grales_Cte\%20 Dchos\%20Ec\%20S- $\%$ oc 20 Cult.html\#GEN6

Comité de Derechos Económicos, Sociales y Culturales. (20 de enero de 2003). Observación general No. 15. El derecho al agua (artículos 11 y 12 del Pacto Internacional de Derechos Económicos, Sociales y Culturales). Disponible en: http:// conf-dts1.unog.ch/1\%20SPA/Tradutek/ Derechos_hum_Base/CESCR/00_1_obs grales_Cte\%20D. $\%$ chos\%20Ec\%20Soc\%20 Cult.html\#GEN15

Consejo de Derechos Humanos de las Naciones Unidas. (28 de marzo de 2008). Resolución $7 / 22$. Los derechos humanos y el acceso al agua potable y el saneamiento. Disponible 
en: http://ap.ohchr.org/documents/S/HRC/ resolutions/A_HRC_RES_7_22.pdf

Corte Interamericana de Derechos Humanos. (2 de septiembre de 2004). Instituto de Reeducación del Menor vs. Paraguay. Disponible en: http://www.corteidh.or.cr/ docs/casos/articulos/seriec_112_esp.pdf

Corte Interamericana de Derechos Humanos. (24 de agosto de 2010). Caso de la Comunidad Xámok Kásek vs. Paraguay. Disponible en: http://www.corteidh.or.cr/docs/casos/ articulos/seriec_214_esp.pdf

Declaración de los Derechos del Hombre y del Ciudadano. (1789). Disponible en: http:// www.sev.gob.mx/educacion-tecnologica/ files/2013/01/3.-Declaracion_de_los_derechos_del_hombre_y_del_ciudadano.pdf

Estrada, R. (2010). Los fundamentos de los derechos humanos. Gaceta de la Comisión Estatal de Derechos Humanos de Jalisco, 60, abril-junio, pp. 70-75.

Euwater, Red. (2005). Declaración europea por una nueva cultura del agua. Cuadernos del CENDES, mayo-agosto, 161-163. Disponible en: http://www.redalyc.org/ articulo.oa?id=40305911

Fernández, E. (2001). Dignidad humana y ciudadanía cosmopolita. Madrid: Dykinson.

Ferrajoli, L. (2001). El fundamento de los derechos fundamentales. Madrid: Trotta.

Ferrajoli, L. (2002). Derechos y garantías. La ley del más débil ( $3^{\mathrm{a}}$ ed.). Madrid: Trotta.

García, A. (2008). El derecho humano al agua. Madrid: Trotta.

Habermas, J. (2010). El concepto de dignidad humana y la utopía realista de los derechos humanos. Diánoia, 55(64), pp. 3-25. Disponible en: http://dialnet.unirioja.es/ buscar/documentos?querysDismax.DOCUMENTAL_TODO $=\mathrm{El}+$ concepto $+\mathrm{de}+\mathrm{di}$ gnidad +humana $+y+$ la +utop $\%$ C3\%AD $\mathrm{a}+$ realista + de + los + derechos + humanos
Howard, G. \& Bartram, J. (2003). La cantidad de agua domiciliaria, el nivel del servicio y la salud (resumen ejecutivo). Disponible en: http://www.who.int/water_sanitation_ health/diseases/wsh0302/es/

Ki-moon, B. (22 de marzo de 2007). Mensaje del secretario general de la ONU con motivo del Día Mundial del Agua. Disponible en: http://www.un.org/es/sg/messages/2007/ worldwaterday2007.html

Ki-moon, B. (22 de marzo de 2009). Mensaje del secretario general de la ONU con motivo del Día Mundial del Agua. Disponible en: http://www.un.org/es/sg/messages/2009/ waterday2009.html

Ki-moon, B. (22 de marzo de 2010). Mensaje del secretario general de la ONU con motivo del Día Mundial del Agua. Disponible en: http://www.un.org/es/events/waterday/ sgmessage_2010.shtml

Ki-moon, B. (22 de marzo de 2011). Mensaje del secretario general de la ONU con motivo del Día Mundial del Agua. Disponible en: http://www.un.org/es/events/waterday/ sgmessage_2011.shtml

Ki-moon, B. (22 de marzo de 2012). Mensaje del secretario general de la ONU con motivo del Día Mundial del Agua. Disponible en: http://www.un.org/es/events/waterday/2012/sgmessage.shtml

Ki-moon, B. (22 de marzo de 2013). Mensaje del secretario general de la ONU con motivo del Día Mundial del Agua. Disponible en: http://www.un.org/es/events/waterday/2013/sgmessage.shtml

Oficina del Alto Comisionado de las Naciones Unidas para los Derechos Humanos. (2011). El derecho al agua. Folleto informativo número 35. Disponible en: http:// www.ohchr.org/Documents/Publications/ FactSheet35sp.pdf

Organización Mundial de la Salud. (2006). Guías para la calidad del agua potable ( $1^{\text {er }}$ apén- 
dice a la $3^{\mathrm{a}}$ ed. Vol. 1. Recomendaciones). Disponible en: http://www.who.int/water_sanitation_health/dwq/gdwq3_es_fu111__owsres.pdf

Peces-Barba, G. (1999). Curso de derechos fundamentales. Teoría general. Madrid: Universidad Carlos III de Madrid.

Peces-Barba, G. (2004). Lecciones de derechos fundamentales. Madrid: Dykinson.

Pelé, A. (2004). Una aproximación al concepto de dignidad humana. Universitas: Revista de Filosofía, Derecho y Política, 1, pp. 9-13.

Pisarello, G. (2003). El Estado social como Estado constitucional: mejores garantías, más democracia. En: V. Abramovich, M. J. Añón \& C. Courtis (comps). Derechos sociales. Instrucciones de uso (pp. 23-54). México D. F.: Distribuciones Fontamara.

Pleno del Tribunal Constitucional Español. (2007). Sentencia 236 de 7 de noviembre.

República de Bolivia. (2009). Constitución Política. Disponible en: http://pdba.georgetown. edu/constitutions/bolivia/bolivia09.html

Riveros, D. F. (2010). Los derechos económicos, sociales y culturales como derechos subjetivos: una visión estructural. Revista de Derecho del Estado, 24, pp. 29-43. Disponible en: http://dialnet.unirioja.es/ buscar/documentos?querysDismax.DOCUMENTAL_TODO $=$ LOS + DERECHOS+EC ONOMICOS+SOCIALES+Y+CULTURA LES+COMO+DERECHOS+SUBJETIVO S+UNA+VISI\%C3\%93N+ESTRUCTURA $\mathrm{L}+\mathrm{DANIEL}+\mathrm{FELIPE}+\mathrm{RIVEROS}+\mathrm{PARDO}$

Rolla, G. (2002). El valor normativo del principio de la dignidad humana. Consideraciones en torno a las constituciones iberoamericanas. Anuario Iberoamericano de Justicia Constitucional, 6, pp. 463-490. Disponible en: http://dialnet.unirioja.es/buscar/ documentos?querysDismax.DOCUMENTAL_TODO=dignidad + humana + rolla

Sánchez, V. M. (2008). Hacia un derecho humano fundamental al agua en el derecho internacional. Revista Electrónica de Estudios Internacionales, 16, pp. 1-23. Disponible en: http://dialnet.unirioja.es/ buscar/documentos?querysDismax.DOCUMENTAL_TODO $=$ hacia + un + derec ho+humano+fundamental +del+agua $+e n+e l+$ derecho + internacional + victo $\mathrm{r}+\mathrm{M} .+$ sanchez. 